\title{
Avaliação de produtividade da cultura da soja semeado sobre três cultivares de Urochloa sp. em SPD e em sistema convencional
}

Evaluation of soybean productivity sown on three cultivars of Urochloa sp. in no-tillage system and conventional system

Evaluación de productividad de la cultura de la soja semeada sobre tres cultivares de Urochloa sp. en siembra directa y en sistema convencional

Samuel Dias Moreira Graduando em Engenharia Agronômica, FCAT/UNESP, Dracena-SP, Brasil sdm.88br@hotmail.com.br

Rafael Simões Tomaz Professor Doutor, FCAT/UNESP, Dracena- SP, Brasil. rafaelst@dracena.unesp.br

Ronaldo Cintra Lima Professor Doutor, FCAT/UNESP, Dracena- SP, Brasil. rclima@dracena.unesp.br 


\section{RESUMO}

A soja é uma das plantas mais cultivadas no mundo sendo a oleaginosa de maior importância econômica para o agronegócio nacional. Associado a essa cultura, o sistema plantio direto (SPD) tem sido utilizado como alternativa sustentável garantindo benefícios ao solo, devido principalmente à quantidade elevada de material orgânico oriundos das plantas de cobertura utilizadas no sistema. Dessa forma, objetivamos com este trabalho avaliar as características agronômicas da cultura da soja em SPD comparando com o sistema convencional, fazendo uso de três gramíneas para fornecimento de palhada. O experimento foi realizado na FCAT- UNESP/Dracena no ano agrícola 2016/2017. O delineamento experimental foi o de blocos casualizados com sete repetições, sendo os tratamentos, forrageiras Ruziziensis, Piatã e Paiaguás, além do preparo convencional do solo. Identificou-se que cobertura Urochloa brizantha cv. BRS Paiaguás e o sistema de plantio convencional proporcionaram maiores produtividades de grãos na cultura da soja, com produção média de 4368 e $4316 \mathrm{~kg} \mathrm{ha}^{-1}$, respectivamente. Ainda, a referida cobertura foi a que mais proporcionou massa seca de resíduos totais, proporcionando maior incremento de matéria orgânica no solo.

PALAVRAS-CHAVE: Planta de cobertura, sistema de plantio, preparo do solo.

\section{SUMMARY}

Soybean are one of the most cultivated plants in the world being the most economically important oleaginous for national agribusiness. Associated with this crop, the no-tillage system has been used as a sustainable alternative guaranteeing benefit to the soil, mainly due to the high amount of organic material from the cover plants used in the system. Thus, the objective of this work was to evaluate the agronomic traits of soybean crop in no-tillage system comparing with the conventional system, using three grasses for straw supply. The experiment was carried out at FCAT-UNESP / Dracena in the agricultural year 2016/2017. The experimental design was a randomized block with seven replications, being the treatments, forage Ruziziensis, Piatã, Paiaguás, in addition to conventional soil preparation. It was identified that Urochloa brizantha cV. BRS Paiaguás and the conventional system provided higher grain yields in the soybean crop, with an average yield of 4368 and $4316 \mathrm{~kg} \mathrm{ha}^{-1}$, respectively. Also, this plant coverage was the one that provided the most dry mass of total residues, providing greater increase of organic matter in the soil.

KEYWORDS: Plant cover, planting system, soil preparation.

\section{RESUMEN}

La soja es una de las plantas más cultivadas en el mundo siendo la oleaginosa de mayor importancia económica para el agronegocio nacional. Asociado a esa cultura, el sistema de siembra directa ha sido utilizado como alternativa sostenible garantizando beneficios al suelo, debido principalmente a la elevada cantidad de material orgánico oriundos de las plantas de cobertura utilizadas en el sistema. De esta forma, objetivamos con este trabajo evaluar las características agronómicas de la cultura de la soja en sistema de siembra directa comparando con el sistema convencional, haciendo uso de tres gramíneas para suministro de paja. El experimento fue realizado en la FCAT- UNESP / Dracena en el año agrícola 2016/2017. El delineamiento experimental fue el de bloques casualizados con siete repeticiones, siendo los tratamientos, forrajeros Ruziziensis, Piatã, Paiaguás, además de la preparación convencional del suelo. Se identificó qué cobertura Urochloa brizantha cv. BRS Paiaguás y el sistema de plantación convencional proporcionaron mayores productividades de granos en la cultura de la soja, con una producción promedio de 4368 y $4316 \mathrm{~kg} \mathrm{ha}^{-1}$, respectivamente. Esta cobertura fue la que más proporcionó masa seca de residuos totales, proporcionando mayor incremento de materia orgánica en el suelo.

PALABRAS CLAVE: Planta de cobertura, sistema de plantación, preparación del suelo. 


\section{INTRODUÇÃO}

A soja é uma das plantas mais cultivadas no mundo, sendo o grão, de grande importância econômica para o agronegócio nacional. Na safra 2015/16 a área cultivada foi de 33,2 milhões de hectares com uma produção de 95,4 milhões de toneladas. A cultura da soja representa $57,12 \%$ da área cultivada do país, permanecendo como principal responsável pelo aumento absoluto de área (CONAB, 2017).

Associado a essa cultura, o sistema plantio direto (SPD) tem sido utilizado como alternativa sustentável garantindo benefícios ao solo, devido principalmente à quantidade elevada de material orgânico oriundos das plantas de cobertura utilizadas no sistema. Alguns dos benefícios do uso deste sistema no aspecto físico são: menor amplitude térmica, redução da perda de solo por erosão, manutenção da microbiota Pacheco et al., (2017), conservação da água no solo Casali et al., (2016); Moraes et al., (2016), redução de plantas daninhas Carvalho et al., (2016) entre outros. Tais contribuições vão além do fator econômico, pois devido a maior conservação do solo em relação ao preparo convencional, será possível garantir que as futuras gerações possam usufruir do mesmo solo, mantendo a qualidade produtiva do mesmo. Para que o SPD seja eficiente é necessário que se adeque uma planta de cobertura, que possa atribuir o máximo de benefícios para o sistema. Vários autores têm estudado os efeitos benéficos das plantas de coberturas sobre a produtividade da cultura da soja, sendo que, cada uma pode contribuir de uma maneira diferente no fornecimento de palhada e também a depender do clima e ambiente produtivo a qual está inserida (TORRES et al., 2014; SILVA et al., 2015; ROSA et al., 2017).

A produtividade da soja pode variar em função da espécie de cobertura utilizada, características do clima sobre a lavoura, características físico-químicas dos solos, pragas, plantas daninhas entre outros fatores de interferência. Em relação às plantas de cobertura, tem sido relatado que a velocidade de decomposição das mesmas quando já dessecadas, varia em função do clima e da atividade dos organismos vivos do solo, permitindo com que seus resíduos permaneçam por mais ou menos tempo (COSTA et al., 2015; PERIN et al., 2015).

A cultura da soja semeada em SPD tem influenciado positivamente na conservação do solo além da diminuição de combustíveis e do uso racional dos recursos naturais. $O$ uso desta tecnologia tem sido relatado na região do município de Dracena- SP, que possui áreas promissoras para produção da cultura da soja, gerando renda, desenvolvimento social e sustentável na região, que hoje sofre com grandes problemas de conservação ambiental. Lupatini et al. (2006) relatou que a região tem sérios problemas de degradação em cerca de $70 \%$ das pastagens, sendo estes devido ao baixo nível tecnológico utilizado pelos produtores da região. Sendo que o uso da cultura da soja utilizada em SPD sobre uma adequada planta de cobertura, de modo a recuperar ou substituir as pastagens degradadas, pode garantir uma diminuição do impacto ambiental já existente nestas áreas em questão. 


\section{OBJETIVO}

Avaliar as características agronômicas da cultura da soja em SPD, semeadas sobre resíduos três de diferentes plantas de coberturas, Urochloa brizantha cv. BRS Paiaguás, Urochloa brizantha cv. BRS Piatã, Urochloa ruziziensis (R. Germ \& Evrard), e em sistema convencional, sem uso de planta cobertura de solo.

\section{MATERIAIS E MÉTODOS}

\section{Área experimental}

O experimento foi conduzido na Área Experimental da Faculdade de Ciências Agrárias e Tecnológicas da UNESP - Câmpus de Dracena, coordenadas: Latitude $21^{\circ} 29^{\prime} \mathrm{S}$ e Longitude $51^{\circ} 52^{\prime} \mathrm{W}$, Altitude média de $420 \mathrm{~m}$. De acordo com a classificação de Köeppen, o clima predominante da região é do tipo $\mathrm{Aw}$, com dados climáticos médios anuais: temperatura $23,97^{\circ} \mathrm{C}$, umidade relativa $64,23 \%$ e precipitação pluvial de $1261 \mathrm{~mm} / \mathrm{ano}$. O solo foi classificado segundo o Sistema Brasileiro de classificação, como ARGISSOLO VERMELHO distrófico (EMBRAPA, 2013).

\section{Implantação e condução do experimento}

De acordo com a metodologia descrita por RAIJ et al., (1996) às análises químicas do solo da camada de $0-20 \mathrm{~cm}$, realizadas antes da instalação do experimento, revelaram os seguintes resultados: $\mathrm{pH}\left(\mathrm{CaCl}_{2}\right.$ 0,01 $\left.\mathrm{mol} \mathrm{L}^{-1}\right) 4,9 ; 22 \mathrm{mmol}_{\mathrm{c}} \mathrm{dm}^{-3} \mathrm{de} \mathrm{H}^{+}+\mathrm{Al}^{3+} ; 14 \mathrm{mmol}_{\mathrm{c}} \mathrm{dm}^{-3}$ de Ca ${ }^{2+} ; 8$ $\mathrm{mmol}_{\mathrm{c}} \mathrm{dm}^{-3}$ de $\mathrm{Mg}^{2+} ; 5,0 \mathrm{mmol}_{\mathrm{c}} \mathrm{dm}^{-3}$ de $\mathrm{K}^{+} ; 8,0 \mathrm{mg} \mathrm{dm}^{-3}$ de $\mathrm{P}$ (P-resina); $14 \mathrm{~g} \mathrm{dm}^{-3}$ de matéria orgânica e $56 \%$ de saturação por bases. Fez o ajuste por meio dos cálculos a fim de elevar a saturação por bases a $70 \%$.

A área do experimento teve como cultura antecessora o milho safrinha em 2016, e na sequência implantação de três forrageiras: Urochloa brizantha cv. BRS Paiaguás, Urochloa brizantha cv. BRS Piatã e Urochloa ruziziensis (R. Germ \& Evrard). As plantas de cobertura serviram para aporte de palhada, sustentabilidade e viabilidade do SPD, sendo semeadas em agosto de 2016 com a semeadora da Marca GIHAL, Modelo GA 2500-E, configurada para plantio direto com cinco linhas espaçadas de $0,45 \mathrm{~m}$. A quantidade de sementes utilizadas foi de $10 \mathrm{~kg} \mathrm{ha}^{-1}$; com valor cultural de (VC=76\%). Para melhor distribuição das sementes, foi utilizado $150 \mathrm{~kg} \mathrm{ha}^{-1}$ de calcário a uma profundidade média de $3 \mathrm{~cm}$.

Para implantação da cultura da soja às forrageiras foram dessecadas com o herbicida glifosato WG na dose de $2,5 \mathrm{~kg} \mathrm{ha}^{-1}$, com volume de calda de $240 \mathrm{~L} \mathrm{ha}^{-1}$ em 18/11/2016. Para a implantação do sistema de semeadura convencional, o preparo de solo foi realizado com grade pesada em seguida por grade niveladora.

A semeadura da soja foi realizada com a mesma semeadora descrita acima em 26/11/2016. Utilizou- se a semente da cultivar Agroeste 3730; com densidade de semeadura de 17 sementes por metro e espaçamento entrelinha de $0,45 \mathrm{~m}$. As sementes foram tratadas com $100 \mathrm{ml}$ de inseticida Standak ${ }^{\circledR}$ Top (p.c.) e inoculante turfoso Masterfix Soja na dose de $200 \mathrm{~g}$ 
$100 \mathrm{~kg}^{-1}$ de sementes. A adubação mineral no sulco de semeadura foi de $385 \mathrm{~kg} \mathrm{ha}^{-1}$ de superfosfato simples e adubação de cobertura com $90 \mathrm{~kg} \mathrm{ha}^{-1}$ de $\mathrm{K}_{2} \mathrm{O}$ no dia 15/12/2016.

O controle de plantas daninhas foi realizado em 03/01/2017 com uso do herbicida glifosato WG na dose de $1,5 \mathrm{~kg} \mathrm{ha}^{-1}$. Para controle preventivo da ferrugem asiática foram feitas três aplicações: do fungicida opera (p.c.) na dose de 0,7 $\mathrm{L} \mathrm{ha}^{-1} \mathrm{em} \mathrm{03/01/2011}$, do fungicida Cypres $300 \mathrm{~mL} \mathrm{ha}^{-1}+600 \mathrm{~mL} \mathrm{ha}^{-1}$ de óleo mineral nimbus em 18/01/2017, e do fungicida Ellatus $200 \mathrm{~g}$ $\mathrm{ha}^{-1}+600 \mathrm{~mL} \mathrm{ha}{ }^{-1}$ de óleo mineral nimbus em 06/02/2017. Para o controle de lagartas e percevejos foram feitas quatro aplicações do inseticida Conect (p.c.) na dose de $1,0 \mathrm{~L} \mathrm{ha}^{-1}$ nas respectivas datas: 03/01; 06/02; 28/02 e 10/03/2017.

\section{Colheita e análise de dados}

A colheita foi realizada em $29 / 03 / 2017$. Para a cultura da soja e plantas de cobertura, foram avaliadas 14 características agronômicas descritas a seguir. Estande final ("Np"): para estas avaliações foram contadas as plantas em três linhas centrais de três metros de cada parcela, sendo esta constituída de cinco linhas de 5 metros. Os valores obtidos foram extrapolados para o número de plantas ha ${ }^{-1}$. Altura de planta ("H"): a altura média das plantas de soja foi determinada pela medição, com régua graduada em centímetros, da distância entre o colo da planta até a extremidade apical em dez plantas por parcela, na época da colheita. Altura de inserção da primeira vagem ("Apv"): para a altura média de inserção da primeira vagem foi adotada a distância entre o colo da planta e a inserção da primeira vagem em dez plantas por parcela. Número de vagens/planta (Vg): foi contado o número de vagens presentes por planta, em dez plantas por parcela, sendo consideradas vagens com um ("V1 $\mathrm{g}^{\prime \prime)}$, com dois ("V2g"), três ("V3g"), quatro grãos ("V4g") e Número de vagens total ("Vt"). Massa de 1000 grãos ("Mmg"): foram avaliadas oito repetições de 100 grãos, cujas massas foram pesadas e ajustadas para 13\% de teor de água, possibilitando estimar a massa de 1000 grãos segundo metodologia descrita por BRASIL (2009). Produtividade de grãos ("Pg"): para esta avaliação foram coletadas as plantas em três linhas centrais de três metros de cada parcela e submetidas à trilha mecânica, e, após a debulha, foram pesados os grãos. A massa de grãos foi corrigida para o grau de umidade de $13 \%$ à base úmida e transformada para $\mathrm{kg} \mathrm{ha}^{-1}$. Determinação da produção de massa seca de palha de braquiária inicial ("Pbi”): após a dessecação e antes da semeadura da cultura da soja. Produção de massa seca da palha de braquiária final ("Pbf"): no momento da colheita da soja foram coletadas palha de braquiária em uma área amostral de $0,9 \mathrm{~m}^{2}$ por parcela, e na sequência acondicionadas em saco de papel e levada para estufa com ventilação de ar forçado a $62^{\circ} \mathrm{C}$ até atingir peso constante, após secas foram pesadas e seus valores extrapolados para massa seca em $\mathrm{kg} \mathrm{ha}^{-1}$. Produção de massa seca de palha de soja ("Ps"): foram determinadas em uma área de 4,05 $\mathrm{m}^{2}$ ( 3 linhas de $3 \mathrm{~m}$, espaçadas de 0,45 m), para esta determinação foram colhidas todas as plantas (feixe) com folhas, galhos, vagens e grãos, na sequência foi determinado o peso úmido total, para a correção para massa seca utilizou 10 plantas completas retiradas do feixe, realizou a degrana das vagens para retirada dos grãos, e por diferença contabilizou o peso total da palha e peso dos grãos úmidos, na sequência as amostras foram acondicionadas em saco de papel e levada para estufa com ventilação de ar forçado a $62^{\circ} \mathrm{C}$ até atingir peso constante, após secas foram pesadas e seus 
valores extrapolados para massa seca de palha e grãos de soja em $\mathrm{kg} \mathrm{ha}^{-1}$. Outra variável determinada foi a massa seca de resíduos total ("Prps"): foi determinada pela soma da massa seca de braquiária final + soja ("Pbf" + "Ps").

Na Figura 1 estão dispostas imagens do experimento de soja implantado em SPD sob palha de braquiária e em sistema de plantio convencional. Na figura, está apresentada a soja nos estádios Vi (A), em estádio reprodutivo e vegetativo (B) e (C); e em final de ciclo (D). Oito das 14 características apresentaram diferenças significativas com respeito aos tratamentos avaliados.

Figura 1: Experimento de soja semeado em SPD em dezembro de 2016. (A) Plantas de soja, semeada em SPD, em estádio Vi. (B) e (C) Soja em estádio reprodutivo e vegetativo. (D) Soja em final ciclo.

(A)

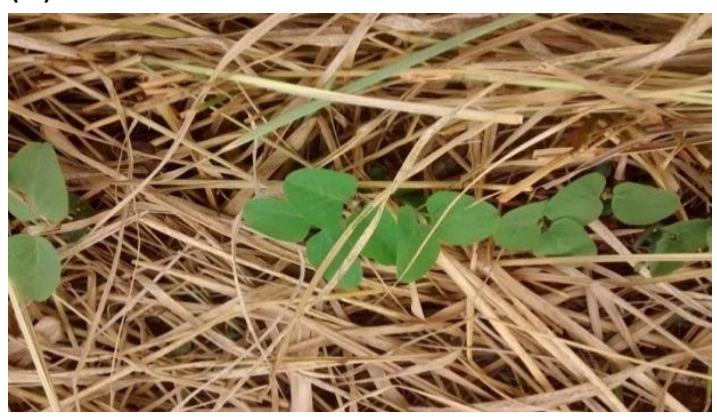

(C)

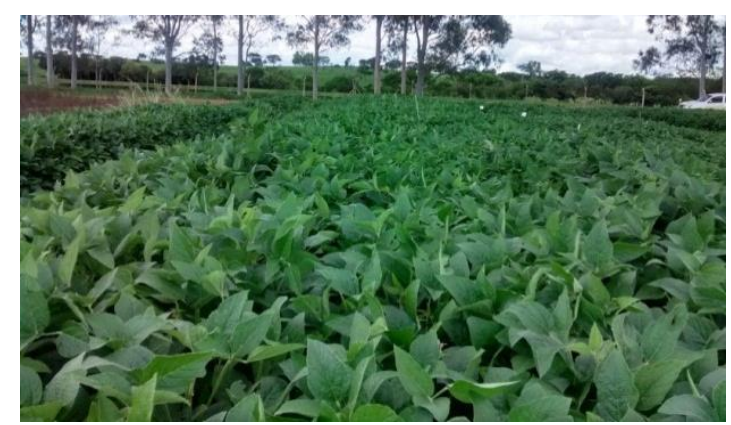

(B)

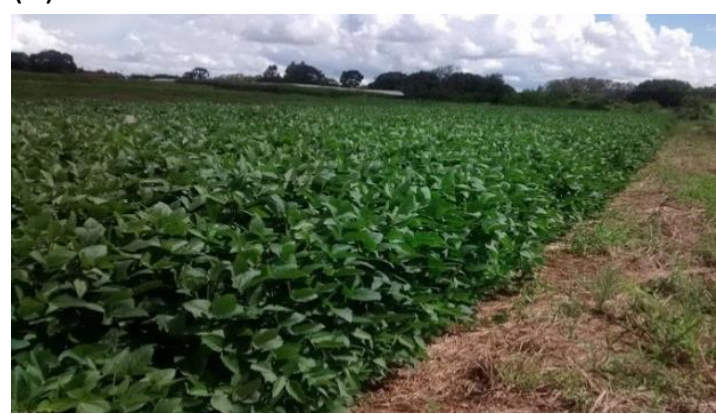

(D)

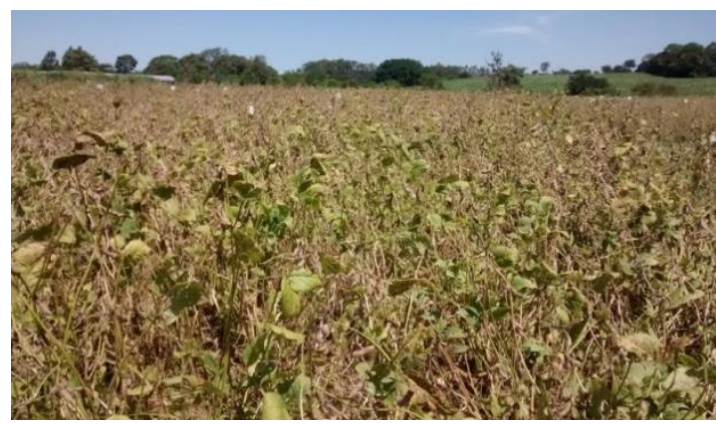

Fonte: Dados de pesquisa, 2017.

\section{Análise estatística}

O experimento foi instalado segundo delineamento de blocos casualizados com sete (7) repetições, sendo os tratamentos as três coberturas utilizadas no SPD, mais o preparo convencional. Para análise dos dados, para cada característica foi realizada análise de variância considerando o modelo estatístico: $Y_{i j}=m+T_{i}+B_{j}+e_{i j}$; em que $Y_{i j}$ corresponde ao valor observado para a variável em estudo referente ao tratamento $i$ no bloco $j ; m$, à média de todas as unidades experimentais para a variável em estudo; $T_{i}$, ao efeito do particular tratamento $i$ no valor observado $Y_{i j}$; $B_{j}$, ao efeito do bloco $j$ no valor observado $Y_{i j}$; e $e_{i j}$, ao erro experimental na observação $Y_{i j}$. Com relação aos tratamentos, foram considerados: $\mathrm{T}_{1}$ - Soja em SPD + U. Ruziziensis; $\mathrm{T}_{2}-$ Soja em SPD + U. Paiaguás; $\mathrm{T}_{3}-$ Soja em SPD + U. Piatã $; \mathrm{T}_{4}$ - Soja em sistema convencional. Para as variáveis que apresentaram significância na análise de 
variância, foi realizado teste de Tukey para comparação de médias. As análises foram realizadas por meio de rotinas desenvolvidas pelos autores no Software livre R ( $R$ Core Team, 2016).

\section{RESULTADOS E DISCUSSÃO}

Na Tabela 1 estão apresentados os resultados da análise de variância para as variáveis: Produtividade de grãos (“Pg"), Número de plantas (“Np"), Altura de planta (“H”), Altura de inserção da primeira vagem ("Apv"), Número de vagens com um ("V1g"), com dois ("V2g"), três ("V3g"), quatro grãos ("V4g"), Número de vagens total ("Vt"), Massa de 1000 grãos ("Mmg"), Produção de massa seca de braquiária inicial ("Pbi"), Produção de massa seca de braquiária final ("Pbf"), Produção de massa seca de palha de soja ("Ps"), Massa seca de resíduos total ("Prps").

A análise dos resultados indicou que todas as características apresentaram boa precisão experimental, excetuando-se "V1g" e "V4g" que apresentaram Coeficientes de Variação (CV) classificados como muito alto, sendo estes superiores a 30\%. De acordo com Pimentel Gomes (1990), o CV é considerado baixo quando inferior a 10\%, médio quando está no intervalo de 10 a $20 \%$, alto quando de 20 a $30 \%$, e muito alto quando superior a $30 \%$. "V2g" e "Ps" apresentaram $\mathrm{CV}$ altos, e todas as demais características apresentaram estimativas inferiores a $20 \%$.

$\mathrm{Na}$ análise de variância, não foi detectada diferenças significativas entre as variáveis "Apv", "V1g", "V2g", "V4g", "Mmg" e "Ps", mensuradas entre os diferentes tratamentos. Para as características " $\mathrm{Pg}$ " e " $\mathrm{H}$ ", foi detectada diferença significativa apenas ao nível de $10 \%$ $(p<0,10)$, sendo o teste de média para essas variáveis também realizadas a este nível de significância. Para a característica "Pg", os tratamentos com Paiaguás e sistema convencional apresentaram médias semelhantes iguais entre si $(p<0,10)$ com produtividades médias de 4368 e $4316 \mathrm{~kg} \mathrm{ha}^{-1}$, respectivamente. Essas médias foram superiores aos tratamentos $U$. ruziziensis e Piatã. Estes tratamentos obtiveram produtividade média 15\% inferiores aos melhores tratamentos. 


\section{$=-20$ Fórum Ambiental}

Tabela 1. Análise de variância para as 14 características avaliadas na cultura da soja semeada em SPD sob três coberturas vegetais e sistema convencional. Produtividade de grãos (Pg), Número de plantas (Np), Altura de planta (H), Altura de inserção da primeira vagem (Apv), Número de vagens com um (V1g), com dois (V2g), três (V3g), quatro grãos (V4g), Número de vagens total (Vt), Massa de 1000 grãos (Mmg), Produção de massa seca de braquiária inicial (Pbi), Produção de massa seca de braquiária final (Pbf), Produção de massa seca de palha de soja (Ps), Massa seca de resíduos total (Prps).

\begin{tabular}{|c|c|c|c|c|c|c|c|c|c|c|c|c|c|c|c|}
\hline \multirow[b]{2}{*}{ FV } & \multirow[b]{2}{*}{$\mathrm{gl}$} & \multicolumn{14}{|c|}{ QM } \\
\hline & & $\mathrm{Pg}$ & $\mathrm{Np}$ & $\mathrm{H}$ & Apv & V1g & V2g & V3g & V4g & $\mathrm{Vt}$ & Mmg & $\mathrm{Pbi}$ & $\mathrm{Pbf}$ & Ps & Prps \\
\hline Tratamento & 3 & $982561^{\circ}$ & $9111486317^{* * *}$ & $193,285^{\circ}$ & 9,587 & 0,036667 & 6,8543 & $82,737^{*}$ & 0,3156 & $138,662 *$ & 33,289 & $148299499 * * *$ & $31891690 * * *$ & 6042979 & $48518823^{* * *}$ \\
\hline Bloco & 6 & 244978 & 1005879039 & 82,291 & 12,12 & 0,045833 & 9,0315 & 22,495 & $0,57786 *$ & 62,089 & $83,579 *$ & $4261467^{\circ}$ & 763614 & 1131538 & 1034618 \\
\hline Resíduo & 18 & 367867 & 801775861 & 62,722 & 10,664 & 0,128056 & 8,0579 & 18,043 & 0,19198 & 43,475 & 28,672 & 1700742 & 368756 & 2692861 & 2979249 \\
\hline CV (\%) & & 15,1 & $9,71 \%$ & 6,33 & 12,80 & 47,71 & 25,77 & 16,76 & 43,97 & 17,31 & 3,41 & 19,3 & 19,71 & 21,34 & 16,03 \\
\hline
\end{tabular}

- $p<0,10 ; * p<0,05 ;{ }^{* *}-p<0,01 ; * * *-p<0,001 . C V$ - Coeficiente de variação.

Fonte: Dados de pesquisa, 2017.

Tabela 2. Teste de comparação de médias das características agronômicas da soja semeada em SPD sob três coberturas vegetais e sistema convencional. Tratamentos seguidos pela mesma letra não diferem entre si pelo teste de Tukey $(\mathrm{p}<0,05)$. Produtividade de grãos (Pg), Número de plantas (Np), Altura de planta $(\mathrm{H})$, Altura de inserção da primeira vagem (Apv), Número de vagens com um (V1g), com dois (V2g), três (V3g), quatro grãos (V4g), Número de vagens total (Vt), Massa de 1000 grãos (Mmg), Produção de massa seca de braquiária inicial (Pbi), Produção de massa seca de braquiária final (Pbf), Produção de massa seca de palha de soja (Ps), Massa seca de resíduos total (Prps).

\begin{tabular}{|c|c|c|c|c|c|c|c|c|c|c|c|c|c|c|}
\hline \multirow[b]{2}{*}{ Tratamento } & \multicolumn{14}{|c|}{ Médias } \\
\hline & $\mathrm{Pg}^{1}$ & $\mathrm{~Np}$ & $\mathrm{H}^{1}$ & $\mathrm{Hpv}$ & V1g & V2g & V3g & V4g & $\mathrm{Vt}$ & $\mathrm{Mmg}$ & $\mathrm{Pbi}$ & $\mathrm{Pbf}$ & Ps & Prps \\
\hline Paiaguás & $4368 a$ & $307937 a$ & $129,03 a$ & 26,67 & 0,73 & 11,17 & $25,57 a b$ & 0,97 & $38,41 a b$ & 155,52 & $7900 b$ & $4179 b$ & 9082 & $13261 a$ \\
\hline Convencional & $4316 a$ & $237743 b$ & $128,48 a$ & 24,11 & 0,86 & 11,83 & $30,10 a$ & 1,30 & $44,07 a$ & 159,34 & Oc & Od & 7169 & $7169 c$ \\
\hline Ruziziensis & $3696 b$ & $314286 a$ & $125,46 a$ & 24,98 & 0,71 & 9,58 & $22,47 b$ & 0,81 & $33,59 b$ & 157,9 & $8923 b$ & $3362 c$ & 7255 & $10617 b$ \\
\hline Piatã & $3692 b$ & $306526 a$ & $117,69 b$ & 26,24 & 0,70 & 11,47 & $23,31 b$ & 0,90 & $36,29 b$ & 154,58 & $10207 a$ & $4781 a$ & 7252 & $12034 b$ \\
\hline
\end{tabular}

1. A significância das variáveis.

Fonte: Dados de pesquisa, 2017. 
Silveira et al. (2014) relatou que produtividade do sistema convencional é superior ao SPD no início de implantação, sendo os processos contínuos de desagregação do solo os causadores da redução de produtividade ao longo do tempo. No entanto, o SPD contribui para diminuir os processos erosivos, e com o processo de mineralização da palhada, disponibiliza nutrientes importantes.

Com relação à característica número de plantas por hectare, todas as coberturas apresentaram resultado superior ao do sistema convencional. Isso pode ser explicado devido alguns fatores benéficos do SPD para o solo, como, maior umidade, menor variação de temperatura, melhor absorção de água, e proteção contra erosões entre outros fatores assim como relataram os autores Belan et al. (2017) e Falci Dechen et al. (2015), o que favoreceu o desenvolvimento e a manutenção do maior número de plantas por unidade de área nos sistemas com uso de plantas de cobertura. Mesmo com uma menor média de plantas por hectare, as médias de produtividade da soja sobre sistema convencional foi de aproximadamente 72 sacas ha $^{-1}$. Segundo Heiffig et al. (2015) isso pode ser explicado pelo fato de a soja possuir um mecanismo de crescimento vegetativo e reprodutivo muito intenso e vigoroso fazendo com que seu desenvolvimento e produtividade compensem uma possível redução não brusca no número de plantas por unidade de área. Porém a produtividade da soja com o resíduo da planta de cobertura Paiaguás foi de aproximadamente 73 sacas ha ${ }^{-1}$.

Para a característica morfológica de altura, as plantas de soja apresentaram menores alturas sobre resíduo de Piatã, sendo inferior estatisticamente das demais $(p<0,10)$. Porém a menor altura de plantas pode ser um dos fatores que proporciona menor número de vagens por planta e consequentemente menor produtividade.

Com relação ao número de vagens com três grãos e número total de vagens as maiores médias foram obtidas com o sistema convencional e no SPD em resíduo de Paiaguás, sendo estes os dois tratamentos que proporcionaram melhores produtividades. O número total de vagens é uma característica influenciada pelo manejo que a cultura recebe, assim como número de plantas por área, número de vagens por planta e o peso de grão. Segundo Silva (2015), a relação entre essas características é de natureza complexa, sendo objeto de muitos estudos.

Pode ser observada uma maior "produção de massa seca de braquiária inicial" para forrageira Piatã, sendo estatisticamente superior às demais. O tratamento com esta forrageira proporcionou um acúmulo de $10207 \mathrm{~kg} \mathrm{ha}^{-1}$ de cobertura vegetal no solo. Paiaguás e Ruziziensis apresentaram médias estatisticamente iguais entre si. No período final do experimento, para a característica de "produção de massa seca de braquiária final", as médias apresentadas para as forrageiras Piatã, Paiaguas e Ruziziensis foram de 4781, 4179 e $3362 \mathrm{~kg}$ $\mathrm{ha}^{-1}$ respectivamente. Sendo a forragem Piatã estatisticamente superior às demais, proporcionando maior acúmulo de material orgânico. Este grande acúmulo de palhada da forrageira Piatã foi devido ao seu vigoroso crescimento vegetativo, tendo sido relatado por diversos autores (NANTES et al., 2013; MAIA et al., 2014; ALVES, 2015; ANDRADE, 2015).

A planta de cobertura Paiaguás foi estatisticamente maior que os demais tratamentos, proporcionando maior Massa seca de resíduos total (resíduos das braquiárias + soja) no solo em relação às demais gramíneas, portanto todas as coberturas foram superiores em relação ao preparo convencional de solo. O uso da gramínea Paiaguás, Piatã e Ruziziensis resultou em um 
incremento de respectivamente 46, 40 e $32 \%$, a mais de Massa seca de resíduos total em relação a semeadura de soja com preparo convencional do solo, demostrando assim, uma maior contribuição de todas as plantas de coberturas para fornecimento de resíduos vegetais para o ambiente produtivo, contribuindo assim, para o uso sustentável do solo.

\section{CONCLUSÕES}

A cobertura Urochloa brizantha cv. BRS Paiaguás e o sistema de plantio convencional proporcionaram maiores produtividades de grãos na cultura soja, com produção média de 4368 e $4316 \mathrm{~kg} \mathrm{ha}^{-1}$, respectivamente. Ainda, a referida cobertura foi a que mais proporcionou massa seca de resíduos totais, proporcionando maior incremento de matéria orgânica no solo.

\section{REFERÊNCIAS BIBLIOGRÁFICAS}

ALVES, L.W.R. Produção e dinâmica de degradação da fitomassa de planta para cobertura do solo no sistema plantio direto em Paragominas, PA. Embrapa Amapá-Boletim de Pesquisa e Desenvolvimento (INFOTECA-E), 2015.

ANDRADE, R. A. S. Acúmulo de biomassa e produção animal em pastos de capim piatã e paiaguás em sistema de integração lavoura-pecuária. Embrapa Gado de Corte-Texto para Discussão (ALICE), 2015.

BELAN, L. L., Xavier, T. M. T., Torres, H., Toledo, J. V., Pezzopane, J. E. M. DINÂMICA ENTRE TEMPERATURAS DO AR E DO SOLO SOB DUAS CONDIÇÕES DE COBERTURA. Revista Acadêmica: Ciência Animal, v. 11, p. 147-154, 2017.

BRASIL. Ministério da Agricultura, Pecuária e Abastecimento. Regras para análise de sementes. Ministério da Agricultura, Pecuária e Abastecimento. Secretaria de Defesa Agropecuária. Brasília, DF: MAPA/ACS, 2009. 395p. http://www.bs.cca.ufsc.br/publicacoes/regras\%20analise\%20sementes.pdf

CARVALHO, W. P., TEIXEIRA, L. G. V., NETO, D. O. A., MOREIRA, J. M. S., \& DA CUNHA, C. E. Alelopatia de resíduos de plantas de cobertura no controle de braquiária cv. Marandu. Revista Brasileira de Biociências, v. 14, n. 2, 2016.

CASALI, C. A., TIECHER, T., KAMINSKI, J., SANTOS, D. R. D., CALEGARI, A., \& PICCIN, R. Benefícios do uso de plantas de cobertura de solo na ciclagem de fósforo. Manejo e conservação do solo e da água em pequenas propriedades rurais no sul do Brasil: práticas alternativas de manejo visando a conservação do solo e da água. Cap. 2, p. 23-33, 2016.

Companhia Nacional de Abastecimento, CONAB. Monitoramento agrícola - Safra 2016/17. Acomp. safra bras. grãos, v. 4 Safra 2016/17 - Oitavo levantamento, Brasília, p. 1-144, 2017.

COSTA, N. R., ANDREOTTI, M., ULIAN, N. D. A., COSTA, B. S., PARIZ, C. M., TEIXEIRA FILHO, M. C. M. Acúmulo de nutrientes e tempo de decomposição da palhada de espécies forrageiras em função de épocas de semeadura. Bioscience Journal. Uberlandia: Univ Federal Uberlandia, v. 31, n. 3, p. 818-829, 2015.

MORAES, M. T., DEBIASI, H., FRANCHIN, J. C., \& DA SILVA, V. R. Benefícios das plantas de cobertura sobre as propriedades físicas do solo. Práticas alternativas de manejo visando a conservação do solo e da água, 2016.

EMPRESA BRASILEIRA DE PESQUISA AGROPECUÁRIA - EMBRAPA. Sistema brasileiro de classificação de solos. 3.ed. Brasília, 2013. 353p.

FALCI DECHEN, S. C., SANTOS TELLES, T., de FÁtIMA GUIMARÃES, M., \& CLERICE de MARIA, I. Perdas e custos associados à erosão hídrica em função de taxas de cobertura do solo. Bragantia, v. 74, n. 2, 2015.

HEIFFIG, L. S., DE SOUSA CÂMARA, G. M., MARQUES, L. A., PEDROSO, D. B., DE STÉfANO PIEDADE, S. M. PLASTICIDADE DA CULTURA DA SOJA (Glycine max (L.) MERRILL) EM DIFERENTES ARRANJOS ESPACIAIS. BRAZILIAN JOURNAL OF AGRICULTURE-Revista de Agricultura, v. 84, n. 3, p. 204-219, 2015. 
LUPATINI, G. C., Medeiros, S. F., Yamamoto, W. K., Ronchesel, J. R., Mingatto, F. E., \& de Figueiredo, P. A. M. Avaliação de pastagens degradadas na região da Nova Alta Paulista. Boletim de Indústria Animal, 65(1), 51-61.

MAIA. G.A.; COSTA, K.A.P.; SEVERIANO, E.C.; EPIFANIO, P.S.; NETO, J.F.; RIBEIRO, M.G.; FERNANDES, P.B.; SILVA, J.F.G.; GONÇALVES. W.G. Yield and Chemical Composition of Brachiaria Forage Grasses in the Off season after Corn Harvest. American Journal of PlantSciences, v.5, p.933-941, 2014.

NANTES, N.N.; EUCLIDES, V.P.B.; MONTAGNER, D.B.; LEMPP, B.; BARBOSA, R.A.; GOIS, P.O. Desempenho animal e características de pastos de capim-piatã submetidos a diferentes intensidades de pastejo. Pesquisa Agropecuária Brasileira, v.48, n.1, p.114-121, 2013.

PACHECO, L., COSTA, R., CUNHA, P., WISINTAINER, C. Atividade microbiana do solo sob plantio direto e incorporado com diferentes palhadas e épocas de aplicação de nitrogênio. Multi-Science Journal, v. 1, n. 6, p. 54-58, 2017.

PERIN, A., CRUVINEL, D. A., DOS SANTOS fERREIRA, H., MELO, G. B., DE LIMA, L. E.,DE SÁ ANDRADE, J. W. DECOMPOSIÇÃO DA PALHADA E PRODUÇÃO DE REPOLHO EM SISTEMA PLANTIO DIRETO. GLOBAL SCIENCE AND TECHNOLOGY, v. 8, n. 2, 2015.

PIMENTEL GOMES, Frederico. Curso de estatística experimental. Piracicaba: Nobel, 1990.

R Core Team (2016). R: A language and environment for statistical computing. R Foundation for Statistical Computing, Vienna, Austria.URL https://www.R-project.org/.

RAIJ, B. van; CANTARELA, H.; QUAGGIO, J.A. \& FURLANI, A.M.C. Recomendações de adubação e calagem para o Estado de São Paulo. 2.ed. Campinas, Instituto Agronômico, 1996. 285p. (Boletim Técnico, 100).

ROSA, D. M., NÓBREGA, L. H., MAULI, M. M., DE LIMA, G. P., PACHECO, F. P. (2017). Substâncias húmicas do solo cultivado com plantas de cobertura em rotação com milho e soja. Revista Ciência Agronômica, v. 48, n. 2, p. 221, 2017.

SILVA, G. F. C., PANACHUKI, E. Infiltração de água no solo em área cultivada com soja sob diferentes sistemas de manejo. ANAIS DO ENIC, v. 1, n. 2, 2015.

SILVEIRA, M. G., OLIVEIRA, A. P. S., MATOS, R. P., SOUSA, C. M., SILVA, F. A.TEORES DE MATÉRIA ORGÂNICA E MACRONUTRIENTES NO SOLO EM FUNÇÃO DE PLANTAS DE COBERTURA. Anais do Simpósio de Pesquisa e Extensão de Ceres e Vale de São Patrício (SIMPEC), 2014.

TORRES, J. L. R., FABIAN, A. J., MAGALHÃES, M. P., ANDRIOLI, I. . Influência de plantas de cobertura na temperatura e umidade do solo na rotação milho-soja em plantio direto. Current Agricultural Science and Technology, v. 12, n. $1,2014$. 